\title{
SIN EXCESOS Y AUTÉNTICAMENTE CHILENO: DISCURSO Y PRÁCTICA DE LA DICTADURA SOBRE EL ROCK ENTRE 1973 Y 1983
}

DANIEL SIERRA*

\begin{abstract}
RESUMEN
La dictadura representó múltiples transformaciones en la sociedad chilena, proceso del que los jóvenes no quedaron exentos. Mediante la creación de organismos públicos, medios de difusión y diversas actividades juveniles, el régimen intentó formar nuevos ciudadanos disciplinados y comprometidos con la reconstrucción nacional. En este artículo se da cuenta de tal proceso, atendiendo a las formas con que la dictadura se encargó de ciertas expresiones artístico-culturales, específicamente el rock, durante sus diez primeros años. Del análisis de diferentes fuentes - especialmente entrevistas a músicos realizadas por el autor y revisión de prensa de la época- llegamos a concluir que el régimen actuó simultáneamente reprimiéndolo, apoyándolo y utilizándolo para distraer, pues dentro del régimen coexistían visiones contrapuestas sobre los jóvenes y la cultura.
\end{abstract}

PALABRAS CLAVE: ROCK, DICTADURA, JUVENTUD

* Licenciado en Historia de la Universidad de Chile. Magíster (c) en Historia de Chile, Universidad de Santiago.

E-Mail: danielernestosierra@gmail.com. 


\title{
SEM EXCESSOS E AUTENTICAMENTE CHILENO: DISCURSO E PRÁTICA DA DITADURA SOBRE O ROCK ENTRE 1973 E 1983
}

\begin{abstract}
RESUMO
A Ditadura representou múltiplas transformações na sociedade chilena, processo do qual os jovens também participaram. Mediante a criação de organismos públicos, mídia e diversas atividades juvenis, o regime tentou formar novos cidadãos disciplinados e comprometidos com a reconstrução nacional. Neste artigo apresento aquele processo, considerando as formas com que a Ditadura foi responsável de certas expressões artístico-culturais, especificamente do rock, durante seus dez primeiros anos. Da análise de diferentes fontes (Especialmente entrevistas realizadas a músicos pelo autor e a revisão de imprensa da época) concluo que o régime agiu simultaneamente reprimindo, apoiando e utilizando o rock para distrair, porque dentro do régime coexistiam visões contrapostas sobre os jovens e a cultura.
\end{abstract}

PALAVRAS CHAVE: ROCK, DITADURA, JUVENTUDE

\section{NO EXCESS AND GENUINELY CHILEAN: DISCOURSE AND PRACTICE OF THE DICTATORSHIP ON THE ROCK MUSIC BETWEEN 1973 AND 1983}

\begin{abstract}
The Dictatorship represented multiple transformations in the Chilean society, a process where young people were not exempted. By creating public organizations, media and various youth activities, the regime tried to forge new disciplined citizens, committed to the national reconstruction. In this article I present that process, considering the ways in which the Dictatorship was responsible for certain artistic-cultural expressions; specifically rock music during its first ten years. From the analysis of different sources (especially interviews with musicians conducted by the author and press review of that time) I concluded that the regime acted simultaneously repressing it, supporting it and using it to distract, because within the regime coexisted opposite points of views about youth and culture.
\end{abstract}

KEY WORDS: ROCK MUSIC, DICTATORSHIP, YOUTH 


\section{INTRODUCCIÓN: JUVENTUD Y CULTURA EN LA INTERPRETACIÓN DE LA DICTADURA}

DE ACUERDO AL CONOCIMIENTO acumulado hasta ahora, durante la dictadura no solo hubo control y represión hacia los jóvenes y la cultura, sino que también, voluntades y mecanismos guiados por el interés de infundir ciertos valores y comportamientos afines al proyecto de reconstrucción nacional (Baño y Kirkwood, 1980; Luco y Pascal, 1990; Muñoz, 2004; Valdivia, 2006). En una mirada panorámica, José Weinstein (1990) ha enfatizado además que el régimen tuvo un comportamiento oscilante hacia los jóvenes de acuerdo a los vaivenes sociopolíticos del país, pudiendo reconocerse tres fases en su desarrollo.

- Desde el Golpe de Estado (septiembre de 1973) hasta las Jornadas de Protesta Nacional (1983-1986). Etapa marcada por la construcción e instalación forzosa de una imagen de juventud homogénea, sin desigualdades socioeconómicas ni compromisos políticos, hija privilegiada de la modernidad. Dicha imagen fue elaborada y difundida por organismos creados especialmente para eso, como la Secretaría Nacional de la Juventud (SNJ), el Instituto de Estudios y Capacitación Diego Portales y la revista Juventud.

- Desde las Jornadas de Protesta Nacional (1983-1986) hasta la coyuntura del Plebiscito (1988). El gobierno, al ver desmentido su discurso de homogeneidad y orden por la movilización social, decidió cambiar su estrategia acentuando las diferencias entre los jóvenes y apuntando como un mal ejemplo al joven popular que se levantaba en protesta, castigándolo ${ }^{1}$. Paralelamente, el ideal del joven consumista - lo que Irene Agurto llamó «modelo juvenil-mercantil»— se levantaba con fuerza en una etapa donde el neoliberalismo ya se imponía como modelo estructural (Agurto y De la Maza, 1985).

- Plebiscito (octubre de 1988). Escenario en que el gobierno intentó retener a los segmentos ya cooptados — pues constituían un reservorio de vital proyección política para la entrante década, ganasen o perdiesen en el referéndum de octubre - y sumar nuevos apoyos

1 A juicio de Víctor Muñoz Tamayo, esto representó una derrota no menor para la dictadura, pues implicaba asumir que las realidades eran diversas y desiguales, trisando su discurso de homogeneidad juvenil (Muñoz, 2004). José Weinstein, por su parte, ha postulado que detrás de este giro se escondió una motivación política que, después de todo, también buscaba perpetuar el discurso de la homogeneidad, ya que con ella justificó las acciones represivas y desacreditó ante la opinión pública las motivaciones de la revuelta (Weinstein, 1990). 
juveniles. Para ello elaboró un discurso convocante, donde el joven patriota, defensor del país, se erigía actor protagónico en el aún inconcluso proceso de reconstrucción nacional. A su vez, desmitificaba y desprestigiaba a la Unidad Popular, haciéndola sinónimo de caos y decadencia.

Si ahora atendemos a la forma con que la dictadura abordó la cultura y el arte, la producción académica sobre el tema ha insistido - ya desde los años 80- que la postura dictatorial no fue exclusivamente represiva, sino que también adoptó una actitud propositiva en la medida que su proyecto planteaba redefinir y refundar la forma de ser de los chilenos. En ese sentido, se puede reconocer la coexistencia de tres líneas inspiradoras de la acción institucional: la primera apostó por la refundación de los valores tradicionales chilenos, subrayando el carácter nacional de la cultura; la segunda enfatizó el desarrollo de una cultura de élite reconocida académicamente; la tercera instaló el mercado como criterio de organización y acción de la cultura y el arte. Las tres visiones coexistieron en una permanente tensión que finalmente fue quebrantada por la supremacía del modelo neoliberal y el progresivo retiro del Estado de esas discusiones terminaron por romper ( $\mathrm{Ri}$ vera, 1983; Catalán y Munizaga, 1986; Subercaseaux, 2006).

Desde ese cruce de visiones acerca de la «juventud» y la «cultura chilena», el régimen intentó definir posturas y acciones sobre el rock, fenómeno que en el país acumulaba poco menos de una década y que parecía atraer cada vez a más jóvenes, aunque en comparación a otras expresiones musicales — como la Nueva Canción Chilena—, resultaba inofensivo en cuanto a contenidos líricos y compromisos políticos de músicos y aficionados. ¿Por qué entonces el régimen invirtió esfuerzos y recursos en el rock ? ¿Y qué formas concretas adoptó su relación con este y sus cultores? En las páginas que siguen proponemos algunas respuestas a esas interrogantes, enfocando el análisis en los diez primeros años del régimen. Esto debido a los importantes cambios que se verifican en la forma en que la dictadura se relacionó con los jóvenes y la cultura, pero también por las renovaciones y transformaciones vividas hacia 1983 dentro del propio circuito de la música rock, en particular, el surgimiento del «Nuevo Pop» con grupos tan influyentes como «Los Prisioneros». 


\section{CONTROL Y REPRESIÓN}

Para los jóvenes rockeros, sobre todo para aquellos de barrios populares y poblaciones, la dictadura fue un período durísimo que dejó en su memoria las huellas del miedo que tiñó las relaciones sociales, a partir de prohibiciones y represalias certeramente aplicadas. «Lo más probable es que siempre terminaras preso», afirma el guitarrista de Amapola, Luis Álvarez, recordando las jornadas de conciertos en discoteques y gimnasios bajo dictadura. «La policía ya iba después no solamente por una cuestión de que había una reunión política, ya era como por deporte: estaban los pelucones (jóvenes de pelo largo), sabían que iba a haber pito (marihuana), sabían que iba a haber copete (alcohol), entonces algo iban a sacar de todas maneras, así que la policía [iba] por último para que los entrenaran». ${ }^{2}$

$\mathrm{Y}$ es que ser joven, provenir de los sectores populares y hacer rock en tiempos de dictadura fue una tarea sumamente compleja. Primero, porque en perspectiva generacional es evidente el ensañamiento que tuvo el régimen con los jóvenes a la hora de controlar y disciplinar a la sociedad civil. ${ }^{3}$ Tal como sostuvo Agurto, de la Maza y Canales (1985), los jóvenes vivían marcados por «el castigo y el aprendizaje forzado de la disciplina» además de la exclusión del mercado de trabajo y educación, aunque con la novedad de que en dictaduras «castigo y exclusión operan sobre un vacío, sobre la desintegración nacional» y con un poder que actúa atomizándolos, distanciándolos. En ese sentido, la creación de la Comisión Chilena Proderechos Juveniles, CODEJU (1978), ${ }^{4}$ ilustra bastante bien la urgencia de atender en su especificidad los numerosos casos de jóvenes víctimas de violaciones (Orellana y Hutchison, 1991).

Visto ahora bajo un lente social, es sabido que la represión fue vivida con especial crueldad por los sectores populares, los que fueron marcados por la rudeza de las detenciones, allanamientos, golpizas y

2 Entrevista a Luis Álvarez, realizada por el autor el 11 de junio de 2012.

3 Para referencias en orden cronológico, revisar el texto Memorias para construir la paz (cronología), publicado por el Arzobispado de Santiago, Fundación Documentación y Archivo de la Vicaría de la Solidaridad.

4 CODEJU. Documento de constitución del consejo pro derechos juveniles CODEJU. CODEJU, Santiago, 1978; Yunge B., Guillermo: Derechos humanos, derechos juveniles: La Comisión Nacional pro Derechos Juveniles de Chile, CODEJU. Instituto para el Nuevo Chile, Rotterdam, 1979. 
amedrentamientos de todo tipo, sin contar los trastornos asociados a la agudización de la injusticia social por los cambios en la estructura económica (Zeiss, 2008). La investigación y elaboración de historias locales en poblaciones como La Legua (ECO, 2012) o La Pincoya (Henríquez, 2012), ha permitido conocer desde cerca los modos en que la represión se hizo carne en estos sectores.

Finalmente, atendiendo al desarrollo del rock desde un plano cultural, vale reparar en un temprano estudio de José J. Brunner (1979) donde se postulaba la existencia de cuatro conjuntos de políticas culturales en dictadura, dos de los cuales corresponderían a políticas represivas como las aquí exploradas:

i) «políticas de exclusión», referidas a la expulsión o eliminación de personas (ejemplo: desaparecidos) y a la negación o impedimento de que algo ocurra (ejemplo: censura, prohibiciones);

ii) "políticas de control», aquellas en que se busca clausurar el espacio público impactando en el ámbito de la comunicación social, la cual se vuelve fragmentaria, intrascendente y privada.

Años más tarde, el estudio sobre cultura y movimiento artístico de Anny Rivera (1983) demostraría que la negación y exclusión de personas, grupos e ideologías, obedecían efectivamente a principios de acción política, implicando la muerte definitiva del fundamento pluralista en cultura. De ahí que circuitos culturales potencialmente críticos al sistema, como el de las «peñas» (González y Bravo, 2009) o el de las universidades (Muñoz Tamayo, 2006) fuesen habitualmente perseguidos, vigilados y castigados.

No es casualidad que entonces que entre los jóvenes rockeros, uno de los primeros dispositivos represivos que experimentaron fue el «toque de queda», 5 pues significó el cambio de ritmos y horarios en sus pautas cotidianas, sobre todo en lo relativo al desarrollo de conciertos: «el toque era muy temprano, y si [el concierto] lo hacías a las ocho en el centro, no había locomoción para volver», recuerda José Aldunate del grupo Millantún (Ponce, 2008). El baterista de Turbamulta, Luis José Hidalgo, recuerda que «[al inicio] no había nada de nada, no había nada de nada ... luego, al tiempo...por ahí por el año 77, 75 más o menos, 75 ó 76 se empieza a recuperar un poco, pero todo hasta antes del toque de queda y sumamente vigilado». ${ }^{6}$

5 Una cronología del «toque de queda» aparece citada en Aguayo (2012).

6 Entrevista a Luis José Hidalgo, 31 de enero de 2011. 
Justamente una de las formas de dar continuidad a los conciertos fue retomar la tradición de las «convivencias», iniciada en parroquias y colegios antes del Golpe de Estado. El guitarrista y fundador de Arena Movediza, Hernán «Nano» Ponce, recuerda que «había toque de queda, entonces tú no podías salir a la calle a las once, ¿qué hacíamos nosotros?: 'oye, nosotros tenemos que seguir tocando' —nos interesaba la música - ‘qué hacemos?' 'Hablemos con estos compadres que tienen un local y hagamos un show desde las tres de la tarde hasta las siete'. Y llegaba la gente a las tres de la tarde, eso hacíamos». ${ }^{7}$

Otra forma de evadir el horario vigilado fueron las llamadas «fiestas de toque a toque», lo que implicaba que los grupos, una vez que se presentaban, debían pasar la noche en los recintos donde se desarrollaban los eventos, hasta que finalizara el toque de queda a la mañana siguiente. Francisco «Panchorrata» Carrasco, guitarrista del sector Pudahuel-Cerro Navia, recuerda que en dichas fiestas: «te quedabai encerrado - no podiai salir - tocando rock hasta cierta hora, pero después música no más ... pero no podiai salir porque los pacos estaban prácticamente [esperando]». ${ }^{8}$

De cualquier forma, el toque de queda nunca dejó de representar una delgada y fatídica línea roja para quienes continuaron haciendo rock, tal como recuerdan los bateristas Mauricio Sierra (Mole) y Ulises Guendelmann (Púrpura), a propósito de conciertos ofrecidos en La Pintana y Estación Central, respectivamente:

Eran un cuarto para las doce de la noche, y estábamos subiéndonos a una camioneta de los curas, y se fueron rajaos, por Santa Rosa, y faltando cinco pa' las doce llegamos a la Plaza Italia. Así que de ahí, me bajé de la camioneta [corriendo] por el Parque Forestal, y con botas, con unas botas que me llegaban aquí arriba, paré, me saqué las botas, las amarré así, y un pique compadre, pasé rajao por La Vega, por la Panamericana, y ya veía que me llegaba el balazo, porque los compadres veían...los milicos jugaban, 'mira, ¿cachai el perro que va allá?'[Imita ruido de disparo] Caía el perro. Una persona, una silueta que iba caminando en 'toque de queda' [Imita ruido de disparo] ¡El balazo poh! ¡Llegué a la casa a las 12 justas! ¡Y yo partí 5 pa' las 12 de Plaza Italia, ¡todo un record!

7 Entrevista a Hernán «Nano» Ponce, 19 de julio de 2012.

8 Entrevista a Francisco «Panchorrata» Carrasco, 14 de agosto de 2012.

9 Entrevista a Mauricio Sierra, 10 de junio de 2012. 
Tocábamos abajo, en una cuestión que se llama Caballero Rojo, debe haber sido el año 78. [...] Para volver teníamos que tomar el último colectivo, bajamos en Matucana con Alameda y venir corriendo desde la Estación Central a la Plaza Bulnes. Y los pacos nos pegaban pero para qué te cuento, nos cortaban el pelo, cualquier show. Todos los días, en el portal Edwards, donde está el Estadio Chile, 'iya, pa' onde van los huevones!'. Los tipos se indignaban por el hecho de que tuvieras el pelo largo. Por la pura pinta ya les caías mal (Ponce, 2008).

Otro de los dispositivos que la dictadura empleó para vigilar a los rockeros fue la exigencia de «permisos» para realizar los conciertos. De acuerdo a los testimonios recopilados, existió un protocolo mediante el cual los productores de conciertos — que muchas veces eran los mismos músicos - debían entregar la información relativa al evento a las autoridades de seguridad local, tal como recuerda Francisco «Pancho» Conejera, músico, periodista y productor durante esos años «estas convivencias se podían seguir haciendo a las cuatro de la tarde, simplemente había que pedir permiso, en términos de especificar dónde se hacía, cuánta gente llegaba, permisos 'tipo' que ya se habían establecido así, con el retén de carabineros más cercano o el cuartel de milicos más cercano». ${ }^{10}$ El guitarrista Luis Álvarez complementa esa información, agregando que con los permisos también se buscaba controlar y censurar las canciones cuyas letras fueran demasiado provocadoras «en esa época, tú si querías tocar tenías que ir a la intendencia, o el tipo que iba a producir el evento tenía que ir y llevar las letras de todos los temas de las bandas que iban a tocar, los número de carnet de cada uno de los integrantes de las bandas que iban a tocar y si a los señores les parecía bien se hacía el concierto, si no, no se hacía ¡y no se hacía!». ${ }^{11}$ Víctor «Poncho» Vergara, bajista y líder del grupo Tumulto, recuerda una anécdota con un productor de eventos que ilustra cómo el miedo se iba instalando en el circuito rock «me llamó un gallo con la exigencia de no cantar en castellano, porque por cualquier cosa que se malinterpretara nos íbamos en cana nosotros y él. Empezamos a tocar covers porque era música en inglés, nadie entendía y era una forma de trabajar» (Ponce, 2008). ${ }^{12}$ Esa visión es compartida por Andrés Godoy, quien estima que «fue tanto el temor generalizado

10 Entrevista a Francisco Conejera, 12 de julio de 2012.

11 Entrevista a Luis Álvarez, 11 de junio de 2012.

12 La expresión cover se utiliza entre los músicos para referirse a una reversión propia de alguna canción preexistente. 
entre las bandas que solo quedaron los covers. La propuesta era nada. Lo vital era tocar» (Ponce, 2008).

Ese «temor generalizado» del que habla Andrés Godoy estuvo alimentado por la presencia de agentes de vigilancia en la entrada de los conciertos. Así lo describe el periodista David Ponce a propósito de un concierto de Tumulto en el Parque O'Higgins «hacia 1977 [tocan] en la Gran Ramada del pueblito del Parque O'Higgins, donde actúan con piquetes militares a cargo del ingreso de los espectadores» (2008). Es también el tiempo de los llamados «sapos», agentes infiltrados en los eventos para saber lo que allí se decía y hacía. Alejandro Martin, baterista de Pooztinga, recuerda con algo de humor «a nosotros nos pasó que donde íbamos andaban dos pacos de hippie, vestidos de hippie, ¡ya se habían hecho amigos de nosotros poh!», reflexionando luego «piensa el clima que se había creado, tú no sabiai a quién teniai al lado, no era tan fácil, el concepto 'sapo' se genera ahí poh, tú podí estar aquí, vacilando, pero no sabí a quién tení al lado, y ese gallo después actuaba en la impunidad, te pescaban y no tenían que rendirle explicaciones a nadie». ${ }^{13}$

Aun con todos estos filtros y medidas de control, no fue raro que los conciertos de todos modos fuesen interrumpidos por efectivos de carabineros o militares, práctica sistemática y violentamente desplegada según recuerda el bajista Willy Pino, del grupo Creciente Moribundo. De acuerdo a su testimonio, al teatro Grajales (Santiago Centro) «llegaban los carabineros, hacían unas redadas impresionantes [y] se los llevaban a todos» (Ponce, 2008), algo que también se vivió en una famosa discoteque de Avenida Carrascal (Quinta Normal), según recuerda el baterista Mauricio Sierra «estábamos tocando ¿en qué discoteque? en La Profecía, llegaron los pacos, ¡todos presos! Nos llevaron a todos presos. ¡Los músicos también!». ${ }^{14}$ Luis José Hidalgo, rememorando un concierto del grupo Teykers al que asistió como público, comentó que «estaban tocando en Recoleta - también nosotros tocamos ahí, pero no me acuerdo cómo se llamaba- y llegaron los carabineros y entraron buscando, y se los llevaron». ${ }^{15}$ Luis Álvarez, por su parte, asevera que «me bajaron encañonado del escenario más de un par de veces, junto con otros». ${ }^{16} \mathrm{El}$ guitarrista Hernán «Na-

13 Entrevista a Alejandro Martin, 19 de noviembre de 2013.

14 Entrevista a Mauricio Sierra, 10 de junio de 2012.

15 Entrevista a Luis José Hidalgo, 31 de enero de 2011.

16 Entrevista a Luis Álvarez, 11 de junio de 2012. 
no» Ponce recuerda detalladamente este tipo de prácticas, a propósito de un concierto en la discoteque Pelo, de la población Bulnes (Renca):

Fue en la [discoteque] Pelo. Resulta que había un horario... por decirte ...hasta las 12 , nosotros tocábamos y estaba lleno, lleno, lleno, era normal ya, nosotros ya sabíamos, ya no era una novedad. De repente estábamos tocando - Los Trapos tocaban ahí también — prendían las luces normales, las luces de colores, y de repente cuando veíamos que ipah! Prendían la luz blanca, 'llegaron los pacos'... se acabó todo.

-Paren, paren paren. llegaba el dueño.

- Las mujeres acá, los hombres acá.

Y nosotros arriba del escenario, no nos bajábamos de ahí, entonces ... de repente llegaban ahí:

— iCarnet de identidad! ¡Usted no tiene! ¡Usted pa’ fuera!

Y llegaban al escenario:

— ¿Bueno ustedes qué...?

- Nosotros somos músicos, estamos trabajando acá.

— ¿Tienen carnet de identidad? ¿Pero tienen derecho a estar aquí trabajando?

- Por supuesto, si nosotros estamos trabajando, nosotros no estamos haciendo nada malo.

— ¿Y ese niño que está atrás?

-Es mi hijo.

—Ah, no, usted no puede estar con niños acá adentro, va detenido.

Y con mi hijo arriba de los camiones, y nos íbamos presos...y mi hijo era feliz poh, cuando se subía a los buses era feliz, era el rey [hace gesto de ir saludando a la gente].

Si cuando uno tocaba, el cincuenta por ciento se iba detenido y el otro cincuenta por ciento ya no funcionaba, por qué: porque se quedaban carabineros afuera y había que cerrar, entonces el dueño decía cerremos mejor, era una manera de decir cerremos, se llevaban la mitad y la otra $\operatorname{mitad} \ldots$ como que se enfriaba todo»». ${ }^{17}$

Si hay un elemento transversal en los testimonios es la sensación de miedo, de «temor generalizado» y que circulaba y crecía a partir de sospechas, denuncias y castigos. El vocalista y guitarrista Andrés Godoy recuerda esos primeros años de dictadura vividos en su natal puerto de San Antonio «no podían andar dos o tres personas juntas, no podías andar con una guitarra; en San Antonio te veían con una guita-

17 Entrevista a Hernán «Nano» Ponce, 19 de julio de 2012. 
rra, pasaban los pacos o pasaban los milicos ¿y estabai con una guitarra? Erai sospechoso al tiro, ¡al tiro!» ${ }^{18}$ El baterista Mauricio Sierra también recuerda cómo la dictadura actuó introduciendo el miedo y las desconfianzas entre sus vecinos de la población Juan Antonio Ríos donde vivió buena parte de su juventud: «una vez estábamos ensayando en la casa con los Mole, en la casa del papá, en la pieza del fondo, y de repente salgo un poco y veo por la ventana [hacia la calle] una gorra de paco que subía y bajaba por la ventana...y salí poh, y estaban los pacos afuera, y hacían así tratando de ver pa' dentro porque escuchaban la bulla, y [el paco] dijo 'bueno, vengo por un llamado de un vecino, que hay... que funciona una discoteque, sin permiso, sin autorización, nada'...» ${ }^{19}$ No hay que olvidar que, después de todo, existía la amenaza latente del castigo, fuese personal o para el circuito de rockeros, como recuerda Luis José Hidalgo a propósito de una sede comunitaria en avenida Sebastopol donde se realizaban conciertos «volvimos a tocar después del Golpe de Estado, como al... ponle tú en noviembre, y llegó la policía a la mitad, en el A.M.A, ${ }^{20}$ y nosotros vestidos de actuación poh, imagínate, y nos sacan a todos pa' la calle, a todos, a todos nos sacan pa' la calle, en el año 73, finales del 73, y de ahí no volvimos a tocar, no se abrió más el local ese, nunca más, nunca más se abrió para eso». ${ }^{21}$

La centralidad con que aparece el miedo en los testimonios permite constatar cómo vivieron algunos jóvenes la experiencia de lo que Moulián llamó una dictadura «revolucionaria-terrorista». En estas, los macabros actos de violación a los DD.HH. - ampliamente documentados en los llamados Informe Rettig (1991) e Informe Valech (2005) deben ser comprendidos en un marco amplio y complejo donde la crueldad, el terror y el castigo cumplen un papel central para destruir antiguas formas de vida e imponer un nuevo orden racional. Para ello, precisamente, usan «el silencio y la economía austera del poder disciplinario combinada con la estridencia y visibilidad del poder represi-

18 Entrevista a Andrés Godoy, 6 de febrero de 2013.

19 Entrevista a Mauricio Sierra, 10 de junio de 2012.

20 De acuerdo a Luis José Hidalgo, la «Sociedad de Ayuda Mutua y Adelanto» (AMA), poseía un espacio (galpón) mutual-sindical ubicado en la población La Castrina. Estaría ubicada en Sebastopol 411, según www.informationpages.com y, de acuerdo a pesquisas recientes, hoy llevaría por nombre «SS.MM. Ayuda Mutua La Castrina (AMA)».

21 Entrevista a Luis José Hidalgo, 31 de enero de 2011. 
vo»; es decir, «el actuar invisible del poder, del cual solo se ven sus efectos, con la furia, en apariencia solo pasional, del castigo» (1998). Para Nicholls y Garcés (2005), en tanto, la extrema violencia fue expresión de una auténtica «lógica de guerra» desarrollada en el pensamiento de las FF.AA. - especialmente del Ejército - cuyo origen se sitúa en el movimiento de contrainsurgencia en Estados Unidos y países latinoamericanos. Además, al interior de las FF.AA., se habría promovido «la noción de que había un poderoso enemigo armado organizado en ejércitos paralelos dispuestos al enfrentamiento» (2005).

\section{EL ROCK PARA FORMAR JÓVENES Y DIFUNDIR VALORES}

Paralelamente al despliegue de los dispositivos de control y castigo, durante la dictadura se crearon organismos y desarrollaron políticas especialmente enfocadas en la promoción de la juventud. A juicio de la historiadora Verónica Valdivia (2006), la represión política desplegada por la dictadura no significó un receso político absoluto, pues el deseo de darle un sentido trascendental a sus acciones derivó en la apertura de pequeños intersticios, espacios donde la actividad social pudo mantenerse, dentro de los márgenes permitidos, y desprovisto de toda aura política (ideológica, de partidos). Esa apertura, sugiere la autora, tenía como propósito la búsqueda y cooptación de los sectores populares, especialmente los jóvenes, adquiriendo gran importancia en esto la creación de la Secretaría Nacional de la Juventud (SNJ). Dicho organismo contó con una publicación periódica, Juventud, que junto al programa «Los Superdiscos» (Radio Nacional) y la organización de festivales-torneos de bandas, se constituyeron en los principales modos que la dictadura tuvo de acercarse a los jóvenes rockeros.

\section{a) El rock en la revista juventud}

Originalmente llamado Boletín Informativo Secretaría Nacional de la Juventud (1975), la revista Juventud expresó a la perfección la coexistencia de visiones diferentes e incluso opuestas acerca de «cultura» y «juventud» dentro de la dictadura. En sus inicios, la publicación difundió la idea del compromiso hacia la nación y sus respectivos valores patrios, promovió la creación de organizaciones afines al régimen - como el Frente Juvenil- y reivindicó el folclor chileno, a la vez que apoyó festivales de la canción juvenil. Sin embargo, a un año de haberse creado, ya era posible notar en sus páginas el resquebraja- 
miento de la visión homogénea presentada por el gobierno, revelando posiciones menos tradicionalistas y más abiertas hacia las influencias foráneas. De ahí que en sus contenidos comenzara a ganar terreno el entonces creciente fenómeno de la onda disco con reportajes a las discoteques y a agrupaciones como ABBA, y también el rock, al mismo tiempo que en otros artículos - con sugerentes títulos como «Consume y cállate»o «El S.O.S. de la música chilena»- se llamaba a los jóvenes chilenos a reflexionar en torno al retroceso de la cultura y los valores locales. $^{22}$

En lo estrictamente relacionado al rock local, Juventud no solo publicó reportajes y fotografías de agrupaciones musicales, sino que además apoyó el desarrollo de certámenes de bandas rock, tema que abordaré en páginas posteriores. Para tener una idea del discurso acerca del rock proyectado desde la revista hacia los jóvenes, conviene leer con especial atención los reportajes «Renacimiento del rock chileno. Ensueño y Miel» y «El renacer del rock chileno», ambos publicados en $1978 .{ }^{23}$ En dichos textos se expusieron tres ideas fundamentales en torno al rock local: la existencia de un pasado «oscuro»; un proceso de renacimiento que estaba en curso hacia finales de los 70; y la búsqueda de un rock verdaderamente chileno como eje central de dicho renacimiento.

En cuanto a la primera idea, la revista afirmó que en el imaginario colectivo el rock estaba rodeado de un aura negativa, asociada a consumos y prácticas inadecuadas para los jóvenes: «[el rock], por diversas razones, ha sido rechazado por muchos sectores por tener una imagen de ser un centro de problemas que se traduce en marihuana, alcohol y muchos arrestos por parte de la policía. Esta imagen se arrastró durante mucho tiempo y era la tónica permanente en cada uno de los recitales que ofrecían los grupos rocks chilenos». ${ }^{24}$ Cabe destacar que los fragmentos recién citados abrían el reportaje, de modo que desde un comienzo se situaba al joven lector frente a una expresión cultural de pasado inequívocamente nefasto.

22 «Consume y cállate», Juventud No 12 , febrero de 1978, p. 37. «El s.O.S. de la música chilena», Juventud $\mathrm{N}^{\circ} 15$, mayo de 1978, p. 30.

23 «Renacimiento del rock chileno: Ensueño y Miel». Juventud $\mathrm{N}^{\circ} 12$, febrero de 1978, pp. 20-21. «Segundo festival musical original del rock nacional. El renacer del rock chileno». Juventud №15, mayo de 1978, pp. 6-7.

24 «Segundo festival musical original del rock nacional...», p. 6. 
Sobre el antecedente anterior se levantó la segunda idea, esto es, que hacia 1978 se estaría viviendo un «renacimiento» del rock chileno. Dicha tesis, explicitada en los títulos de ambos reportajes analizados, daba cuenta del nuevo momento por el que estaba pasando el rock local tras años de oscuridad «hoy en día, después de un receso de aproximadamente cinco años, esta manifestación de la música popular ha alcanzado un nuevo auge. [...] El rock chileno está renaciendo y tiene - si los grupos continúan por este rumbo- buenas perspectivas dentro del ámbito musical nacional». ${ }^{25}$ Es importante constatar que en el concepto de la revista, este renacimiento se producía después de un «receso» de cinco años, vale decir, justamente después del Golpe de Estado y hasta la fecha de publicación (1978), lo que dejaba en evidencia el deseo de la revista oficialista por destacar la supuesta resurrección del rock antes que las razones de su bajo desarrollo anterior.

Finalmente, la tercera idea a subrayar es que el renacimiento descrito estaría marcado especialmente por el interés de reencontrar una especie de rock «nacional», acorde a la cultura local y sacudido de influencias extranjeras «se busca crear una nueva música rock chilena, basándose en las raíces folclóricas. Labor que debe ser apoyada desde todos los puntos de vista, para poner en movimiento un rock auténtico, sin copias». ${ }^{26}$ No es un detalle menor que en ambos reportajes se utilizó la frase «como una forma de reencontrar lo que es el verdadero rock nacional» para encabezar la presentación de cada texto, lo que se tradujo en un rescate de aquellas bandas musicales que a juicio de la revista aportaban en la elaboración de un rock más chileno. Así, del grupo Ensueño se afirmó que «trata de mantener una cierta idiosincrasia respecto del rock, cuestión poco usual en grupos de esta naturaleza», ${ }^{27}$ mientras que en la nota sobre un certamen-festival de bandas rock, publicó la siguiente declaración dada por el grupo ganador, Arena Movediza «esto es un estímulo para seguir haciendo cosas. Creemos que ganamos porque arriba del escenario fuimos Arena Movedi$\mathrm{za}$, sin influencias extranjeras. Somos originales». ${ }^{28}$

25 «Renacimiento del rock chileno: Ensueño y Miel...», pp. 20-21.

26 «Segundo festival musical original del rock nacional...», p. 7.

27 «Renacimiento del rock chileno: Ensueño y Miel»..., p. 21.

28 «El renacer del rock chileno»..., p. 7. 


\section{b) «Los superdiscos» y el «Club de los amigos del rock»}

«Los Superdiscos» fue un espacio abierto en Radio Nacional - emisora oficial de la dictadura - que entre 1978 y 1982 aproximadamente, estuvo dedicado específicamente a difundir y comentar rock local y anglosajón. Juan Miguel Sepúlveda, emblemático conductor del programa, tuvo la compleja misión de lidiar con las dificultades propias de un medio oficialista en circunstancias de que su propia infancia y juventud habían estado ligadas a experiencias que lo acercaban más al mundo social, aunque sin militancias de tipo político. Hacia 1981, el locutor afirmaba que uno de los sentidos profundos del programa era - tal como se vio con la revista Juventud - hacer frente a la embestida de expresiones culturales foráneas movidas por intereses comerciales: «[Los Superdiscos está] dirigido a toda la juventud que se siente un tanto desamparada por parte de la radiotelefonía que, en su afán de comercializar cada espacio, ha creado una odiosa competencia olvidándose de la 'otra música' que también tiene importancia en todo tipo de público». Y añade «conscientes de que hay buenos exponentes rockeros en el país, [Radio Nacional] acudió en su ayuda en estos momentos en que es bombardeado por una abrumadora cantidad de material discográfico extranjero, mucho de ello sin valor en el aporte creativo como es la monótona música disco». ${ }^{29}$ No está de más recordar que precisamente la revista Juventud había comenzado hacia 1978 a publicar algunas notas sobre la onda disco, evidenciando una vez más la coexistencia de miradas contrapuestas dentro del gobierno en temas culturales y relativos a las juventudes.

El programa se convirtió en un pilar fundamental para el desarrollo del rock local, sobre todo porque difundió bandas que apenas contaban con grabaciones artesanales de sus canciones, todo ello en un contexto en que la industria musical se encontraba en un paupérrimo estado post Golpe solamente aliviado por la aparición de pequeños sellos discográficos como Atenas y Star Sound. ${ }^{30}$ Más recientemente, el locutor recordó que «muchas veces los mismos chiquillos hacían sus 'demos' en las casas, frente a alguna grabadora, y nosotros los tocábamos igual y eso tenía valor», agregando que «de repente tocábamos a los grupos [extranjeros], no sé poh, Premiata Forneria Marconi y después, atracito, tocábamos un Poozitunga y los compadres se

29 «Los Superdiscos»: Vanguardia de la Música Rock en FM-AM». Candilejas, 4 de marzo de 1981.

30 Algunas precisiones estadísticas sobre ese tema en Salas (2003:108-109). 
habían puesto [a grabar] en su casa, un amigo les prestó un estudio, no sé ... medio 'cachento', sonaba mal, ipero no importa! Lo valioso era eso, era lo rústico, que no tenían ni uno pero podían hacerlo». ${ }^{31}$

El locutor también organizó junto a Gonzalo Kittsteiner, programador musical de la emisora, el «Club de Amigos del Rock» (CAR), un colectivo de adolescentes oyentes de «Los Superdiscos» que tuvo distintas motivaciones y funciones según se desprende de las palabras de Juan M. Sepúlveda: «era como la encuesta C.E.P. que hacíamos para ver cuánta gente teníamos y de dónde nos estaban escuchando, entonces nos dimos ese [trabajo] de poder agradecer a la gente, estar con ellos, sentirlos más cercanos a nosotros», añadiendo que «en el programa me dirigía hablándoles a ellos, yo hablaba en el programa, conversaba con ellos en el programa, entonces eso les gustaba a ellos, era su amigo, yo decía 'compadre', yo hablaba de 'compadre', entonces todos me decían 'compadre'. [El CAR] era para agradecer la sintonía, para comprometerlos más, darles algunas facilidades para ingresar [a los conciertos] - era más barata la entrada para ellos—, los teníamos más informados». ${ }^{32}$

Sin embargo, en el testimonio de Juan M. Sepúlveda también se revela cómo el CAR adquirió otro tipo de funciones mucho más cercanas a la idea de control y vigilancia desplegada por la dictadura. Hacia comienzos de los $80-\mathrm{y}$ al revés de lo que Juventud difundía un par de años antes- los conciertos rock se habían transformado en verdaderas calderas y válvulas de escape, experimentando permanentemente la represión policial como vimos anteriormente. Fue debido a ello que comenzó a gestarse la idea de instalar una «barrera» o «guardias» que resguardaran las distancias entre el público y las bandas, para así evitar desórdenes y destrozos. Allí es donde aparece el CAR «a veces los compadritos se volaban adentro, tiraban botellas, había quedado un poquito la embarrá. En el Estadio Chile por ejemplo, dejamos ingresar primero a todos los que llegaban con el carnet [del CAR], entonces los primeros que llegaban, los mil, tres mil que llegaban con el carnet, los colocábamos alrededor del escenario... molesta la segregación pero no teníamos esas vallas papales, no había nada». ${ }^{33}$

31 Entrevista a Juan Miguel Sepúlveda, 1 de agosto de 2013.

32 Entrevista a Juan Miguel Sepúlveda, 1 de agosto de 2013.

33 Entrevista a Juan Miguel Sepúlveda, 1 de agosto de 2013. 


\section{c) Los festivales masivos apoyados por la dictadura}

Finalmente, hay que referirse a los festivales masivos de rock organizados con el apoyo de Juventud y «Los Superdiscos». Sabemos que algunos de ellos tuvieron carácter de certamen, como el «Segundo Festival de la Canción Original de Rock Chileno» (abril de 1978, Teatro Caupolicán), con tres jornadas que convocaron en total unas 15.000 personas y que premió a Arena Movediza con la grabación del single «Palabras». ${ }^{34}$ Pero sin duda los eventos más recordados por los jóvenes de esa generación fueron las dos versiones del Festival Seis Horas de Música y Amistad, realizadas el 13 de diciembre de 1980 y el 7 de marzo de 1981, respectivamente, además de una tercera versión realizada en el Estadio Municipal de La Reina bajo el nombre de «Primer Encuentro Chileno de Música Contemporánea», celebrado el 19 de diciembre de 1981.

Aunque solo contamos con un puñado de referencias escritas sobre estos eventos, éstas nos ofrecen algunas pistas acerca de sus propósitos de fondo. En relación al festival-certamen de 1978, Juventud señaló «como una forma de reencontrar lo que es el verdadero rock nacional, se organizó el segundo festival de rock original en el Teatro Caupolicán», y si bien «aún no hay una personalidad propia» y «priman las influencias de grupos extranjeros», «existe una búsqueda de un estilo, de una identificación, un tratar de hacer algo nuevo, algo nuestro». ${ }^{35}$ Por su parte, el entonces presidente de la Asociación de Periodistas de Espectáculos y miembro del jurado, Ítalo Pasalcqua, se refirió al festival de bandas en los siguientes términos «los conjuntos que llegaron a este festival, son gente de calidad, que están tratando de hacer cosas. Además son distintos entre ellos, no existe lo de tiempos atrás, en donde todos tocaban igual. Ahora hay un estilo claro en cada uno de ellos, algunos identificables con cosas de afuera, otros no. En todo caso, en general, se está tratando de hacer un rock nuestro con calidad», agregando que «se está rompiendo con la idea del marihuanero, del drogadicto, o sea hay algo más que va fuera de eso...». ${ }^{36}$

Un espíritu similar pareció animar los festivales Seis Horas de Música y Amistad. Una idea básica fue reunir a los músicos y seguidores del rock en un mismo evento para contribuir a su difusión, tal

34 «El renacer del rock chileno», Juventud $\mathrm{N}^{\circ} 15$, mayo de 1978, pp. 6-7.

35 Ibídem.

36 Ibídem. 
como entonces lo expresó Juan M. Sepúlveda: «[la idea] es mostrar que en Chile también hay buenos elementos dentro de la música rock, que aportan calidad», ${ }^{37}$ agregando en otro lugar que «el objetivo fundamental de esta iniciativa, es brindar, por intermedio de Radio Nacional en Frecuencia Modulada, un apoyo significativo al rock nacional que en realidad lo necesita, ya que los conjuntos que intervienen en esta oportunidad, se han esforzado para destacar con esta música que tiene tantos exponentes en el extranjero». ${ }^{38}$ Ese apoyo, no obstante, también estuvo dirigido a proyectar una imagen limpia y renovada del rock nacional (tal como ocurría con los festivales-certámenes comentados más atrás), pues en palabras de Sepúlveda uno de los objetivos era «demostrar que tras esta música solamente existe gente que la sigue en forma sana y no como muchas personas que hacen aparecer este movimiento musical como dañino y pernicioso para la sociedad», ${ }^{39}$ algo que también quedó explicitado en una pequeña nota del periódico La Tercera «aparte de darle a la juventud capitalina la oportunidad de gozar de un extenso recital con la música que a ellos les gusta, e interpretada por conjuntos nacionales, los realizadores del espectáculo quieren demostrar que los lolos chilenos que gustan de la música rock pueden reunirse por miles sin recurrir a la marihuana $\mathrm{u}$ otras drogas, en un encuentro bien organizado».

\section{EL ROCK PARA DISTRAER}

A juicio de Irene Agurto, frente a movimientos juveniles de sello básicamente cultural «la respuesta desde el orden, junto con admitir un margen de tolerancia hacia este tipo de manifestaciones culturales juveniles, tiende a ser más cooptador que represor», de suerte que «un mecanismo clásico es vaciar de contenido crítico algunas expresiones y reconvertirlos en bienes de consumo masivo (el rock, por ejemplo), cuidando de señalar los límites 'juveniles' de dichas manifestaciones»

37 «Festival de Rock en el Estadio Nacional». Candilejas, 10 de diciembre de 1980.

38 «Esta tarde es la fiesta del rock en el Nacional». La Nación, 13 de diciembre de 1980, p. 3C.

39 «Festival de Rock en el Estadio Nacional». Candilejas, 10 de diciembre de 1980.

40 «Seis horas de rock en el court del Nacional». La Tercera, 21 de diciembre de 1980. 
(1985). En el caso acá analizado, si bien la dictadura pareció utilizar el rock para «distraer», no hubo un vaciamiento para venderlo y consumirlo masivamente en tanto bien transable - como fue la tónica ya más entrados en los 80 con la consolidación del neoliberalismo - sino con el doble sentido de «despistar» y «entretener».

La primera acepción quedó retratada con dureza en el documental de Carmen Luz Parot, Estadio Nacional, donde uno de los detenidos en el recinto recuerda cómo la música rock era pasada por los altavoces para ocultar los alaridos de aquellos que eran torturados en el velódromo anexo al estadio: «un soldado me condujo a estas últimas [graderías del Velódromo] y me unió a un grupo de once detenidos. Luego ordenó ponerme la frazada encima de la cabeza, a modo de capucha como el resto, esperé horas y horas. Sutilmente abrí los hilos y pude mirar por un pequeño agujero. En alguna parte cercana a la Avenida Pedro de Valdivia habían instalado un altavoz que diariamente transmitía música de los Beatles y los Rolling Stones, a todo volumen, pero bastante lejos, para que los transeúntes y los escolares de un colegio próximo no oyeran los gritos de quienes estaban siendo interrogados». ${ }^{41}$

La segunda acepción puede reconocerse en algunos relatos de los grupos rock Los Trapos y Tumulto, dos bandas bien distintas en su origen social y circuito de conciertos. La periodista Marisol García afirmó que en los primeros años de dictadura, Los Trapos «fueron invitados a varias fiestas en regimientos militares y recintos de la Fuerza Aérea», algo que fue posible por la tecnología de sus equipos, el origen acomodado de sus integrantes y su opción de no inmiscuirse en debates políticos para evitar el cierre de las puertas. «No eran tiempos fáciles, pero era buen trabajo, y jamás vivimos algo desagradable», recuerda su guitarrista Eduardo Valenzuela. «Como regía el toque de queda, nos íbamos a la casa con salvoconductos que nos daban los mismos militares» (García, 2013). Desde los sectores más populares, el grupo Tumulto también participó en algunas de esas fiestas para los cadetes más jóvenes «una vez, en el regimiento Buin, cuando salimos nosotros toda la plana mayor se retiró. Que los 'pelados' se divirtieran era lo que querían. Nos sacaron en andas. Quizá cuánto tiempo llevaban acuartelados» (Ponce, 2008).

Cabe subrayar que dentro de Tumulto, quien tenía los contactos con los militares era Sergio del Río (ex Los Jockers), cuya situación

41 Carmen Luz Parot: Estadio Nacional, 2002. 
acomodada le permitió generar inigualables oportunidades de trabajo con los grupos rock donde estuviera participando: «y nos iba el descueve $[\ldots]$ todo es un legado de Los Jockers. Yo era súper conocido, independientemente de con quién estuviera (tocando). Pagaban bien, no teníamos ni uno, tú sabes cómo es la música. Eran como los conciertos que daba Elvis Presley en la Marina. Después del golpe militar la verdad es que no había nada que hacer» (Ponce, 2008). Distinta es la visión del bajista y líder histórico de la agrupación, «Poncho» Vergara, quien afirmó «era una situación bien controvertida [...], empezamos a tocar a beneficio por un movimiento que se publicitó como la reconstrucción del país. Eran shows en la calle, la gente hacía donaciones, todavía no se conocía de masacres ni fusilamientos», pero «luego empezó otro tipo de presión contra los músicos, los actores. Las mismas autoridades se empezaron a retobar con esa gente. Andaba mucho sapo. Descubrieron gente asesinada, sucesos más pesados, y se produjo una contracción». Al mismo tiempo, «los medios de comunicación inculcaron el patriotismo, y entre ellos estaba el Canal 9 con «Música Libre». Ellos hacían shows en los regimientos para los que estaban haciendo el servicio militar» (Ponce, 2008).

Basado en ambos testimonios, se puede inferir que la participación de grupos rock en eventos militares obedeció no solo a intereses laborales-económicos, sino que además fue importante el discurso oficial sobre la reconstrucción del país y la labor que a los jóvenes les competía en esa misión, algo que según vimos en páginas anteriores también estuvo presente en revistas, programas radiales y festivales rock apoyados por la dictadura. Es importante enfatizar que la gran mayoría de los jóvenes rockeros no estuvo realmente involucrada en militancias ni luchas políticas, de modo que solo el paso de los años le fue revelando los verdaderos alcances de la represión, de ahí que en un comienzo no hubiese mayores cuestionamientos a involucrarse en actos oficiales como los recién descritos.

\section{CONCLUSIONES}

A juzgar por la documentación revisada, no cabe duda que frente al avance del rock entre los jóvenes chilenos, el régimen militar intentó situarse en un punto intermedio, equidistante entre las posiciones más conservadoras y aquellas más liberales que cohabitaban en la matriz teórica que fundaba sus acciones. Ello se tradujo en la cooptación y «saneamiento» del fenómeno rock, controlando sus excesos y vacián- 
dolo de su contenido más provocador, para luego dotarlo de una imagen que mezclaba en partes iguales el rescate de lo nacional con la promoción de la moral y las buenas costumbres entre los jóvenes.

De ahí que los episodios de represión recordados por los rockeros se asocien especialmente a lo que ocurría durante y después de los conciertos, siendo muy escasos los testimonios que se refieren a hostigamientos o atropellos en otro contexto. En nuestra interpretación, lo que inquietaba a los agentes era la reunión y sinergia que se producía en esos eventos, aún cuando no hubiese canciones «de protesta» (pues ese filtro ya lo habían aplicado en el protocolo de los «permisos»). A ojos del poder, el peligro radicaba en las conversaciones que se daba entre los jóvenes asistentes, el encuentro cercano de sus cuerpos, el retejido de las pequeñas complicidades, los consumos y excesos de drogas y alcohol, la potencia de los amplificadores y la performance de los grupos. Todos esos ingredientes hicieron de los conciertos rock experiencias juveniles sumamente densas, bombas de tiempo que atemorizaban al gobierno, sobre todo por los efectos socioculturales $-\mathrm{y}$ eventualmente políticos - que pudiera acarrear en el futuro. Así, más que los desbordes puntuales vividos en cada jornada de rock, lo que parecía realmente preocupante al régimen era la acumulación de estas experiencias en el mediano y largo plazo, y su eventual estallido a nivel de cimientos amenazando el proyecto de la dictadura, que es lo que en cierto sentido ocurrió en el segundo tercio de los 80 durante las Jornadas de Protesta Nacional. Por eso interrumpían los conciertos antes que ocurriese nada, pues, como recuerda «Nano» Ponce de Arena Movediza, con la acción disuasiva «como que se enfriaba todo», obligando al cese de la actividad. ${ }^{42}$

Bajo esa mirada, la complejidad que la dictadura supuso para los jóvenes no estuvo dada exclusivamente por la represión sufrida en carne propia, sino que también por el cercenamiento de sus propios proyectos de vida y la imposición de un nuevo horizonte en el cual enmarcar los nuevos, como fue el proyecto de reconstrucción nacional levantado en dictadura. Eso explica la preocupación por parte del régimen de reforzar ciertos valores y prácticas entre los jóvenes, a la vez que tomaba resguardos para impedir que «la política» volviera a ser parte de las conversaciones y acciones juveniles, aunque aquello era en sí mismo una decisión y acción sumamente «política».

42 Entrevista a Hernán «Nano» Ponce, 19 de julio de 2012. 
En ese sentido, es notable el rol que jugaron organismos como la ANJ y el cúmulo de actividades de formación y recreación organizados y/o apoyados por ella, pues fue a través de éstos que la dictadura se encargó de eliminar y reemplazar aquellos referentes identitarios que pudiesen evocar una juventud más participativa, crítica y transformadora. Por eso es que en publicaciones de la época, como la revista Juventud $\mathrm{u}$ otras más generales como Chile. Ayer y hoy, abundaron imágenes de jóvenes en actitud de estudio, buena conducta y trabajo: era el tipo de jóvenes que requería el país para resurgir de las cenizas.

Como puede verse, el ámbito de la cultura devino en un escenario donde se confrontaron diferentes proyectos políticos y sociales, y desde donde la dictadura buscó tomar contacto directo con los jóvenes para involucrarlos en el suyo. El rock, en ese sentido, no fue una excepción, y al tiempo que castigó sus desbordes también lo utilizó para vehiculizar referentes y valores ad hoc al régimen o, en el peor de los casos, para distraer - ocultando o divirtiendo, según analizamos-. Debía tratarse de un rock sin excesos y auténticamente chileno, a la medida de los nuevos tiempos impuestos por la dictadura.

SANTIAGo (ChILE), OCTUBRE 2014

RECIBIDO: OCTUBRE 2014 ACEPTADO: DICIEMBRE 2014

43 Chile. Ayer y hoy. Editorial Gabriela Mistral, Santiago, 1975. 


\section{REFERENCIAS BIBLIOGRÁFICAS}

Aguayo, Emiliano (2012): Las voces de los 80. Conversaciones con los protagonistas del fenómeno pop-rock. Santiago: Ril Editores.

Agurto, IRENE y GONZALO DE LA MAZA (1985): «Ser joven poblador en Chile hoy». En IRENE AGURTO et al.: Juventud chilena. Razones y subversiones. Santiago: ECO-FOLICO-SEPADE.

—_— y MANUEL CANALES (1985): «La juventud como intento. La perspectiva teórica». En IRENE AGURTO et al.: Juventud chilena. Razones y subversiones. Santiago: ECO-FOLICO-SEPADE.

BAÑO, RODRIGO Y JULIETA KIRKWOOD (1980): «Términos de interpretación del problema juvenil». Documento de Trabajo N93. Santiago: FLACSO.

BRUNNER, JOSÉ JOAQUÍN (1979): «La estructuración autoritaria del espacio creativo». Documento de Trabajo, s/n. Santiago: FLACSO.

Catalán, Carlos y Giselle Munizaga (1986): Políticas culturales estatales. Santiago: CENECA.

CODEJU (1978): Documento de constitución del consejo pro derechos juveniles CODEJU. Santiago: CODEJU.

COMISIÓN NACIONAL DE LA VERDAD Y RECONCILIACIÓN (1991): Informe de la Comisión Nacional de Verdad y Reconciliación: Santiago, febrero de 1991. Santiago: Secretaría General de Gobierno, Secretaría de Comunicación y Cultura.

ECO, EduCACIÓN y COMUNICACIÓN (2012): La Población la Legua: desde la historia oral hacia la historia local. Santiago: ECO.

EdtTorial Gabriela Mistral (1975): Chile. Ayer y hoy. Santiago: Editorial Gabriela Mistral.

GARCÉS, MARIO y NANCY NiCHOLLS(2005): Para una historia de los derechos humanos en Chile: historia institucional de la Fundación de Ayuda Social de las Iglesias Cristianas (FASIC) 1975-1991. Santiago: LOM-FASIC.

GARCÍA, MARISOL (2013): Canción valiente. 1960-1989: Tres décadas de canto social y político en Chile. Santiago: Ediciones B.

GONZÁLEZ, CRISTIÁN y GABRIELA BRAVO (2009): Ecos del tiempo subterráneo. Las peñas en Santiago durante el régimen militar (1973-1983). Santiago: LOM.

HenRíQueZ, MARCElo y PABlo ZaldívaR (2012): «Entre la resistencia contra la dictadura y una propuesta alternativa: la experiencia de la juventud pincoyana en la dictadura militar, 1980-1990. Un rescate de la memoria rebelde desde nuestra trinchera actual». Informe de Seminario para optar al grado de Licenciatura en Historia. Santiago: Universidad de Chile, Facultad de Filosofía y Humanidades, Departamento de Historia.

LuCO, CRISTIÁN y CRISTÓBAL PASCAL (1990): «Notas acerca de la Secretaría Nacional de la Juventud». En Generación Compiladores: Los jóvenes en Chile Hoy. Santiago: CIDE, CIEPLAN, INCH, PSI PIRQUE, SUR. 
MinisTERIO DEL INTERIOR (2005): Chile. Comisión Nacional sobre la Prisión Política y Tortura: Informe de la Comisión Nacional Sobre la Prisión Política y Tortura. Santiago: Ministerio del Interior, Comisión Nacional sobre Prisión Política y Tortura.

Moulián, Tomás (1998): Chile actual. Anatomía de un mito. Santiago: LOM. MUÑOZ TAMAYO, VíCTOR (2004): «Imágenes y estudios cuantitativos en la construcción social de la juventud chilena. Un acercamiento histórico (2003-1967)». Última Década N²0. Viña del Mar: Ediciones CIDPA.

ORELlanA, PATRICIO y ElIZABETH QUAY HUTCHISON (1991): El movimiento de Derechos Humanos en Chile, 1973-1990. Santiago: Centro de Estudios Políticos Latinoamericanos Simón Bolívar.

PALET, ENRIQUE (S/F): «1983-1986. El auge de la movilización social». Memorias para construir la paz (cronología). Arzobispado de Santiago, Fundación Documentación y Archivo de la Vicaría de la Solidaridad. Disponible en: www.archivovicaria.cl.

Ponce, DAVID (2008): Prueba de sonido. Primeras historias del rock en Chile (1956-1984). Santiago: Ediciones B.

RIVERA, ANNY (1983): Transformaciones culturales y movimiento artístico en el orden autoritario. Santiago: CENECA.

SALAS, FABIO (2003): La primavera terrestre. Cartografías del rock chileno y la nueva canción chilena. Santiago: Editorial Cuarto Propio.

SUBERCASEAUX, BERNARDO (2006): «Cultura y democracia». En EDUARDO CARRASCO y BÁRBARA NEGRÓN (eds.): La cultura durante el período de la transición a la democracia. 1990-2005. Santiago: Consejo Nacional de la Cultura y de las Artes Chile.

VALDIVIA, VERÓNICA (2006): «Lecciones de una revolución: Jaime Guzmán y los gremialistas, 1973-1980». En VERÓNICA VALDIVIA et al.: Su revolución contra nuestra revolución. Izquierdas y derechas en el Chile de Pinochet (1973-1981). Santiago: LOM.

WEINSTEIN, JOSÉ (1990): Los jóvenes pobladores y el Estado.Una relación difícil. Santiago: CIDE.

Yunge B., GuILleRMo (1979): Derechos humanos, derechos juveniles: la Comisión Nacional Pro Derechos Juveniles de Chile, CODEJU. Rotterdam: Instituto para el Nuevo Chile.

ZEISS, SEBASTIÁN (2008): «El actor popular poblacional en el movimiento social contra la dictadura». Tesis para optar al título de sociólogo. Santiago: Universidad de Chile, Facultad de Ciencia Sociales, Sociología.

\section{FUENTES ESCRITAS}

\section{Candilejas}

Juventud

Diario La Nación

Diario La Tercera 


\section{FUENTES AUDIOVISUALES}

PAROT, CARMEN LuZ: Estadio Nacional. Chile, 2002.

\section{ENTREVISTAS}

AlejANDro Martin, baterista grupo Poozitunga (19 de noviembre de 2013). ANDRÉS GODOY, guitarrista y vocalista grupo Andrés, Ernesto y Alejaica (6 de febrero de 2013).

FRANCISCO «PANCHO»CONEJERA, guitarrista grupo Los Mortis y periodista musical (12 de julio de 2012).

FRANCISCO «PANCHORRATA» CARRASCO, guitarrista y productor musical (14 de agosto de 2012).

HERNÁN «NANO»PONCE, guitarrista y vocalista grupo Arena Movediza (19 de julio de 2012).

JuAN Miguel SEPÚlVEDA, locutor radial del programa «Los Superdiscos» (1 de agosto de 2013).

LUIS ÁlVAREZ, guitarrista grupo Amapola (11 de junio de 2012).

LUIS JosÉ HIDALGO, baterista grupo Turba Multa (31 de enero de 2011).

MAURICIO SIERRA, baterista grupo Mole (10 de junio de 2012). 